\title{
LA MUERTE EN LA PAMPA. LAS REPRESENTACIONES DE LA MUERTE EN LA POESÍA DE LOS OBREROS DEL SALITRE CHILENO (1890-1910) $)^{1}$
}

\author{
DEATH IN THE PAMPA. REPRESENTATIONS OF DEATH IN \\ THE POETRY OF CHILEAN NITRATE WORKERS (1890-1910)
}

\section{MIGUEL ÁNGEL MANSILLA***}

\section{RESUMEN}

Este artículo trata de las representaciones de la muerte que tuvieron los poetas obreros del salitre. La muerte es tragedia, precariedad e indignidad y, como la vida de los obreros, tiene esas connotaciones, la vida deviene en muerte. Ellos se conciben como moribundos, muertos antes de morir. Pero no es porque disfruten del morir, sino porque conciben la vida como un fallecer a cada momento y ven en el trabajo la posibilidad indeseada de la muerte. Sin embargo, pese a ser víctimas, no son pasivos: utilizan la muerte como recurso para protestar contra las condiciones de vida y de trabajo que padecían, como una forma de morir protestando. Y optan por la gran muerte o la muerte fértil, que está en la lucha y en la escritura.

Palabras claves: Muerte, obreros, desierto, poesía.

\section{ABSTRACT}

This article deals with representations of death in the poetry of nitrate worker poets. Death is tragedy, precariousness and unworthiness, and as the lives of workers, have these connotations, life turns into death. The workers conceive themselves as dying, dead even before their death. But this is not because they enjoy death but rather be-

${ }^{1}$ Todos los poemas los extrajimos de: González, Sergio; Illanes, Angélica; y Moulian, Luis (eds.). Poemario popular de Tarapacá. 1899-1910, Lom, Dibam, Santiago, 1998. Quiero aprovechar también de agradecer los comentarios y sugerencias a este trabajo del doctor Sergio González, un erudito en el tema salitrero. También deseo extender mis agradecimientos a los evaluadores quienes con sus sugerencias me han permitido finalizar este artículo de una forma más compacta y coherente.

* Sociólogo. Dr. en Antropología. Investigador del Instituto de Estudios Internacionales (INTE) de la Universidad Arturo Prat. Santiago, Chile. E-mail: mansilla.miguel@gmail.com 
cause they conceive of life as a death at every turn and look at work as the unwanted possibility of death. However, despite being victims, they are not passive: they use death as a resource to protest living conditions and the work they have to endure, as a way to die protesting. And they opt for the high death or fertile death fertile which is in the struggle and in writing.

Key words: Death, workers, desert, poetry.

Recibido: 02.11.13. Aceptado: 10.03.14.

\section{INTRODUCCIÓN}

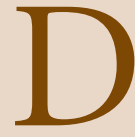

AMOS POR ENTENDIDO que la poesía es un pensamiento socialmente construido e históricamente situado; "por lo tanto, como todo pensamiento, tiene una historicidad inevitable" (Berger y Luckmann 2003: 17). En este sentido la poesía obrera deviene en un recurso muy importante para acercarnos a la realidad social de los trabajadores del Chile de fines del siglo XIX y comienzos del siglo XX. El objetivo de este trabajo es conocer las distintas representaciones de la muerte en la conciencia de los obreros, y que se expresan en la poesía del propio trabajador pampino. Para ello nos hacemos algunas preguntas: ¿Qué significa la muerte para los obreros? ¿Qué referencia sobre la muerte tienen ellos? ¿Por qué la muerte es un tema frecuente en la poesía obrera? ¿Cuáles son las formas más frecuentes de morir? ¿Qué simboliza la muerte para los obreros? ¿Cómo la enfrentan?

En Chile encontramos varios estudios que se refieren al vínculo de la poesía con la muerte ${ }^{2}$, como una forma de "escribir para no morir" (Blanchot, 2002: 82). Sólo por mencionar algunos, Neruda (Campos 1987: 100) logró plantearlo crítica y poéticamente cuando habla de la "pequeña muerte" y la "poderosa muerte". Para Oscar Hahn (Galindo, 2000) la muerte no se vive como participación, sino como concepto. Hahn (Campos, 1987: 101-125) aborda la muerte recurriendo a danza de la muerte y la visión macabra, adquiriendo una función políticamente transgresora. Por otra parte, en la poesía de Enrique Lihn (Espinoza, 2000) la muerte es representada por la figuración de la "viejecita"; y en "la antipoesía de Parra (Triviños, 2007: 45), la muerte se hunde y se inscribe en la vida".

\footnotetext{
${ }^{2}$ Triviños y Aldunate (2006: 63-86); Campos (1987); Belli (1989: 111-112); Lihn (1989: 99104); Galindo (2000: 167-181); Triviños (2007: 35-52); Espinoza (2000: 151-166; Triviños (1993).
} 
La presencia y la forma de la muerte es un tema vastísimo, con innumerables estudios críticos, y aparece como una constante en la poesía chilena. No obstante, queremos centrarnos en la poesía hecha por "no-poetas", personas comunes y corrientes -nuestros poetas obreros-. Estos utilizaron la poesía -en la cual la muerte constituye una realidad ubicua, como recurso y estrategia de protesta social, política y económica. Los obreros no son seres pasivos, sino que enfrentan la muerte de distintas formas: una de ellas es escribiendo, quizás porque ellos pensaban que "escribir nos cambia, porque somos aquello que escribimos" (Blanchot, 2002: 77). Por ello nos pregunta-

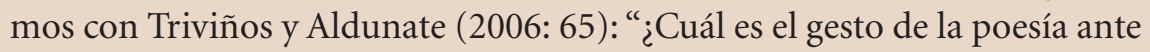
el gesto nulo de la muerte? ¿Qué relaciones se descubren en esa proximidad de la poesía con la muerte?”. O es sólo ¿ “angustia que se hace canto, palabra que es puro movimiento de morir”? (Blanchot, 2002: 128).

\section{MORIR DE HAMBRE}

Los obreros manifiestan un fuerte rechazo a la Iglesia. Esto se hace notorio en el poema anónimo "A un fraile": “... que para morir de hambre/ Es preferible, en verdad,/ Que nos den el coletazo/ Que trae el juicio final./ Así...de una vez; de un golpe/ El mundo se arreglará/ Y nos vamos a la... muerte por toda una eternidad..." . Morir de hambre o morir luchando es el dilema. Morir de hambre "es la muerte injusta" (Blanchot, 2002: 79), por ello es preferible morir en la lucha. Morir luchando se relaciona con el "morir contento, expresando, en primer término, descontento de la vida, la exclusión de la felicidad de vivir, esa felicidad que hay que desear y amar ante todo" (Blanchot, 2002: 80). Otro autor escribe: “... Arriba la abundancia /.../ Y se entregan al goce de la gula/ Todos los habitantes del palacio/ ¡Se mueren nuestros hijos!/ (Exclaman desde abajo)/ Y se mueren de hambre y no podemos/ Todos nuestros recursos/Se encuentran agotados/ Y la fiebre devora nuestros cuerpos/ Y el dolor debilita nuestro ánimo..." ${ }^{\text {4. La }}$ muerte nunca ha sido un fenómeno homogéneo, sino diferenciado social, cultural e históricamente. Las condiciones de la vida hacen la diferencia en las condiciones del morir. La muerte como suceso: arriba, en medio de la abundancia; abajo, en el hambre; arriba, avanzados de edad; abajo, prematuramente; arriba, los hijos nacen y crecen; abajo, los niños mueren de

${ }^{3}$ Anónimo, El Pueblo, septiembre 7, 1899.

${ }^{4}$ Gil Blas. Los de arriba y los de abajo, El Pueblo, julio 21, 1900. 
hambre. Porque "unos y otros ven en la muerte la posibilidad. Aquellos para mantenerla a distancia y éstos para alcanzarla dignamente" (Blanchot, 2002: 82).

Abajo mueren prematuramente $y$, a los que siguen viviendo, el hambre los mata pausadamente. Otro poeta dice: "Desgraciado, desgraciado/ Es sin duda el proletario/ Que aquí viene entusiasmado/ Y sucumbe en el Calvario / .../ Llega a la pampa el obrero/ Y después triste lamento/ ¡Halla acá su carcelero!/ Trabaja con noble anhelo/Por conseguir su sustento.../ Muere en el hospital, hambriento.../ Esa es vida de roto...Muere, o queda en la orfandad"5. Aquí es el trabajo el que mata. La vida del roto ${ }^{6}$ es doblemente miserable, porque las opciones que se le presentan son morirse de hambre o matarse trabajando. La pampa es para el trabajador lo que el calvario era para Roma: un campo de sacrificio. En la poesía obrera nortina, el obrero es presentado como un mártir del capitalismo, un condenado a muerte: las oficinas salitreras son mazmorras donde se muere lentamente. Pero a pesar de esta tragedia hay que luchar por todos los frentes posibles. Una de esas formas de lucha es la poesía. Es una forma de trabajo y combate. "Ese trabajo es escribir. Se aparta del mundo para escribir, y escribe para morir en paz. Ahora, la muerte contenta, es el salario del arte, es el objetivo y la justificación de la escritura. Escribir para morir tranquilamente" (Blanchot, 2002:80). Aunque la muerte sea una fémina insoslayable que está en el hambre, las viviendas, la comida, el trabajo y el camino, hay que luchar. Esto nos muestra que "no sólo cuando mueren sino cuando viven, estos héroes, se mueven en el espacio de la muerte" (Blanchot, 2002: 80). Otro poema, "Hambre y desesperación”, destaca: “... Mas, noto cuando despierto, / Que todo fue un desvarío,/ Que estoy de hambre casi muerto,/ Con el bolsillo desierto/Y el estómago vacío..."7. Lo que acentúa el poema era una triste realidad que en Chile venía desde hacía mucho tiempo. No sólo el hambre mataba, también podía matar la comida. A principio del siglo XX, la calidad de la leche era un producto contaminado, por sus condiciones desde la ordeña hasta la mezcla con agua (Aguilera y Zúñiga, 2006). El pan, el sustento fundamental del pueblo, también se constituía en un alimento mortal, ya sea por las condiciones explotadoras y miserables de los panade-

${ }^{5}$ Lorito. Of. Ramírez. El Pueblo, octubre 28, 1902.

${ }^{6}$ Para ver una etimología y una aclaración al concepto de roto ver: Guzmán, Nicomedes, 1957. "Epopeya del 'roto' chileno". En Autorretrato de Chile. Santiago de Chile: Zig-Zag, pp. 133147.

${ }^{7}$ Luis Ortúzar. Santiago. El Pueblo, mayo 6, 1905. 
ros, las constantes subidas del precio de la harina (Yáñez, 2008: 508) o la inmundicia en la elaboración ${ }^{8}$. Luego los salarios de hambre, que significaba que los obreros no tenían dinero suficiente para comprar comida. No obstante la muerte no le roba la voluntad a estos obreros, sino que se apropian de su corta vida para escribir, aunque ellos no disfruten de esos beneficios, porque "sólo se puede escribir cuando se es dueño de sí frente a la muerte y cuando se establecen con ella relaciones de soberanía" (Blanchot, 2002: 78).

Las condiciones explotadoras impelen a la lucha y es lo que se aprecia en “iA la lucha!”: “¿Qué más esperas pueblo soberano/ Que estás herido y sin embargo callas/ Temes acaso molestar a tu "tirano"/ O tienes miedo a sus sables y metrallas?/ Es verdad que la lucha será cruel/ Por tener que matarnos entre hermanos.../ A nosotros nos quedan dos caminos/ Morir de hambre o emplear la dinamita!"'. Aparece de nuevo la opción morir de hambre o morir luchando. Esto es porque "son capaces de satisfacerse con la muerte, de encontrar en la suprema insatisfacción la suprema satisfacción y de mantener en el instante de morir la mirada clara que proviene de tal equilibrio" (Blanchot, 2002: 79). No obstante la lucha implica huelga, lo que se traduce en no "ganar el pan diario" y arriesgar a la familia al hambre absoluta, sólo morigerada con las solidarias "ollas comunes". En segundo lugar, las marchas y protestas eran disueltas con una fuerte represión, lo que se traducía en muerte y sangre para muchos obreros. Por lo tanto, se pasaba de ganar el pan con el sudor de la frente a ganarlo con la sangre. Así, los obreros prefieren elegir morir a ser condenados a morir.

\section{MORIR TRABAJANDO}

Marx (1987) fue uno de los autores que más denunció las condiciones del trabajo en la fábrica como una antesala del sepulcro. De igual forma lo hizo Baudrillard (1993), para quien el trabajo es una muerte lenta. Ambos autores concuerdan en que los obreros establecieron "una intimidad con la muerte desgraciada" (Blanchot, 2002: 79). Estas muertes desgraciadas eran

\footnotetext{
${ }^{8}$ También hay que sumar a esto la adulteración del pan, algo que también describió Marx en Inglaterra. Sarcásticamente señaló: "El hombre había nacido para ganarse el pan con el sudor de su frente, pero resulta que el pan estaba mezclado con sudor humano, pero también supuraciones de pústulas, telas de araña, cucarachas muertas y avena podrida, arena y otros ingredientes minerales igualmente agradables" (Marx, 1987: 193).

${ }^{9}$ M.A. Orellana. El Pueblo Obrero, diciembre 15, 1906.
} 
observadas y experimentadas por los obreros en la pampa salitrera. Ante el inútil reclamo sólo se ve como posibilidad la lucha y la violencia. El poema "Quintillas" nos dice: " $¡ Y$ en vez de llorar combate $;. . . /$ Que el hombre vino a la tierra/ Para luchar y sufrir;/ Por eso está siempre en guerra/ Por eso es que no se aterra.../Y aquel que sufre no espere /..../ Id a luchar sin tardanza...”10. Ya no son suficientes las lágrimas o el lamento jaculatorio. La violencia es el único medio para lograr los derechos laborales. Ante la muerte por inanición es preferible morir por el gemir del fuego de las balas. La vida del obrero es guerra y dolor. La muerte que trae la huelga o las protestas, sólo es el fin de la condena de la muerte pausada. La violencia se ve como el único recurso para el logro de derechos. Es una violencia reactiva ${ }^{11}$. Pero no es la violencia de todos contra todos, sino de obreros contra burgueses, de pobres contra ricos, de explotados contra explotadores. Si bien los burgueses se separan de los obreros para vivir en paz, los obreros "no se separan de los hombres para vivir en paz, sino para poder morir en paz" (Blanchot, 2002: 80).

Frente a este morir sin descanso, es mejor ir a luchar por los derechos laborales. Este morir luchando y este morir escribiendo implica que "lo mejor que se ha escrito se basa en la capacidad de poder morir contento" (Blanchot, 2002: 78). Por lo tanto, aunque sea un dilema morir trabajando o morir en la lucha, con lo último se logra calma, paz y memoria. En "Poesías", el poeta dice: “...Ya se creen propietarios / De la pampa salitrera/ Transformados en panteras/ Son del pobre, victimarios/ Gime y llora el operario/ De su suerte maldecida/ Porque le quitan la vida/ Los avaros indolentes/ Que se llevan diariamente/ Ahorcando día a día...." ${ }^{12}$. Si trabajar significa vivir triste, entonces hay que hacerse de "la capacidad de escribir para morir bien” (Blanchot, 2002: 79). Morir bien es morir luchando. ¿Por qué? Porque no se muere luchando para sí, sino para bien de todos los obreros. Los obreros no buscan apropiarse del espacio sino compartirlo. En cambio los burgueses son representados como "una pantera" que, como todo felino, marca su territorio con sus orines y heces. Aquí la metáfora félida es similar a la de Baldomero Lillo (2008: 108), quien habla de la araña (el patrón) y la mosca (el obrero). Pero los obreros salitreros "no quieren morir como moscas" (Blanchot, 2002: 114), sino luchar. Aunque sea una víctima que sabe que va a morir, frente al poder del puma (patrón). Asociar

${ }^{10}$ A. Man T. Ojancos. El Pueblo, abril 4, 1900.

11 "Es aquella empleada en la defensa de la vida, de la libertad, de la dignidad, de la propiedad. Este tipo de violencia está al servicio de la vida, no de la muerte: su finalidad es la conservación, no la destrucción" (Fromm, 1992: 21).

${ }^{12}$ Of. Lorenzo, Felipe M. Garcés, El Pueblo, marzo 19, 1903. 
la muerte a la metáfora fáunica es algo que también aparece en Hahn (Galindo 2000: 171). La víctima es anónima, es un tabú. Como toda víctima, es inocente, débil y útil. Un objeto alimenticio. El victimario, en cambio, mata para vivir y es un animal insaciable. Sin embargo, el obrero solidariza con otras víctimas, transforma a sus líderes en héroes. Sólo así "puede mirarlos serenamente y unirse a su muerte con una intimidad porque, por una razón u otra, se tiende serenamente sobre su lecho de muerte" (Blanchot, 2002: 79).

En el poema "Natura”, se lee: “... El obrero va al taller/ En busca de su pan diario/Estando allí su calvario/ ¡pues allá va a perecer..." ${ }^{3}$. Un aspecto muy significativo del pensamiento de los obreros es la alta valoración que asume el trabajo para ganar su propio pan. Ellos no piden una sociedad sin trabajo, sino que buscan mejores condiciones de trabajo. Son críticos y sarcásticos con los curas, militares y patrones, porque no trabajaban como el obrero. Por otro lado, el taller se concibe como un espacio mortuorio del obrero (Marx, 1987: 197). El taller es el calvario del obrero. Esta referencia expiatoria de la nada, también aparece en Oscar Hahn (Galindo, 2000: 173) y Armando Uribe (Triviños y Aldunate, 2006: 75), pues estas criaturas son abandonadas por la divinidad. De esta manera los obreros se unen al gran sentimiento de soledad que embarga la literatura latinoamericana. En su soledad, "afronta la muerte a través de la escritura. La obra es lo que hace la muerte vana, transfigurada, o según las palabras evasivas, menos amarga, menos ingloriosa y tal vez menos probable" (Blanchot, 2002: 81), aunque escriban para morir. Empero esta escritura le dará vida y los unirá a todos los que viven en los siglos de la soledad o se encuentren en los laberintos de los desterrados.

El poema "La pampa de Chile” dice: “... Las dos de la mañana.../ baja la frente, con la ¡Muerte al lado!.../ ¡La ilusión de ser libre solo alegra/ esas almas preñadas de pesares!/ Y en medio de la noche infame y larga!.../ parecen los obreros, trabajando.../ condenados que Dios, por suerte amarga,/ tuviera en el infierno, castigando!" 14 . Emergen dos metáforas significativas, los obreros como los "condenados de Dios" y el espacio laboral como "castigo del infierno". Los condenados de Dios son los obreros que se traducen en obreros-pobres y pobres-obreros: los solitarios de la tierra. Porque "para los pobres no hay Dios" (Lillo, 2008: 133). Es una soledad social, existencial y cósmica. Ellos no fueron puestos en la tierra, sino que fueron arrojados

${ }^{13}$ Roberto Herrera. Of. Pampa Rica. El Pueblo, enero 25, 1906.

${ }^{14}$ Alejandro Escobar y Carvallo. El Pueblo Obrero, diciembre 21, 1909. 
y condenados a trabajar. En cuanto al espacio laboral como castigo del infierno (al igual que Prometeo y Sísifo), éste se ve como tierra de oscuridad y de fuego, representación que también aparece en Oscar Hahn (Campos, 1987: 114): "la imagen del fuego correspondiente a la energía mortal". Entre los poetas obreros, la fábrica y la pampa, juntas, confabulan para cortar los hilos de la vida del obrero. Sin embargo la condena, la soledad y el exilio, son "las razones que le llevan a escribir, para ponerse al abrigo de la muerte" (Blanchot, 2002: 82).

En el mismo poema leemos: “... El campamento que el obrero asila/ vieja prisión de miserables.../ un Cementerio trajinado a ratos.../ Todo es ahí mortificante y gris.../Y los cachuchos de insaciable boca.../ Donde hervir hasta el vapor la Muerte/ Al desgraciado que su turno toca!... ${ }^{15}$. Los obreros "por amor a la vida, desean una muerte por completo diferente, una muerte libre y consciente, sin azar y sin sorpresa" (Blanchot, 2002: 84), pero en los campamentos mineros la muerte es azarosa para los obreros. Hay una metáfora: la cárcel y el cementerio. Ambas explicitan el carácter privativo y caliginoso de los campamentos. La metáfora carcelaria, que alude a la idea de una galera, un espacio laboral de condena donde no existe la libertad. Es algo que también se destaca en Enrique Lihn (Espinoza, 2000), una ciudad donde todos se han encerrado a morir sólo es posible crear líneas de fuga a partir de dos puntos: el sueño y la memoria. Ambas cosas, el sueño y la memoria, se reúnen en la poesía obrera como una forma del buen morir (Blanchot, 2002). Por otra parte, al relacionar el campamento con el cementerio es porque los trabajadores que viven allí son espantajos. Y para rematar la escena se resaltan los cachuchos, que son representados como la imagen de la muerte caliente, la muerte infernal. La muerte acecha al obrero esperando cortar pronto los hilos de la vida. Es la Parca con toda su oscuridad. Luego continúa: “... Así los años por su frente bajan,/Sin que su noble corazón se aflija!/ Cuando sus huesos, de crujir se rajan.../ En el suicidio su ilusión se fija! ..." ${ }^{16}$. Esto se refiere al envejecimiento precoz del trabajador minero (Lillo, 2008: 129). Ante condiciones laborales tan abrumadoras, los hombres envejecían precozmente y mueren laboralmente. Es decir es un "morir antes de la muerte". Por ello los suicidios son frecuentes en la pampa (González, 2007: 27). Esta es la muerte estéril. Pero también estaba la posibilidad de "escribir para poder morir. Morir para poder escribir” (Blanchot, 2002: 81) como muerte fértil.

\footnotetext{
${ }^{15}$ Alejandro Escobar y Carvallo. El Pueblo Obrero, diciembre 21, 1909.

16 Ídem.
} 


\section{LA POLÍTICA DE LA MUERTE}

El Estado en esta época es la "metáfora teratógena" (Hobbes, 1998): se vincula a la muerte física y la muerte eterna, la violencia física y la violencia simbólica, sin importar qué tipo de Estado sea. Como dice Blanchot (2002: 85): "el miedo a la muerte es el origen de Dios; por lo tanto morir significa derrocar a Dios" ¿Quién es este dios? Es el dios mortal, llamado Estado (Hobbes, 1998; Hegel, 1997). Este poder estatal se manifiesta en la figura de un general, como lo destaca el poema Hoja de laurel17: “... ¡Y tú, Gran Capitán.../ al país defendiste en tu batalla/ y colmaste de gloria a la milicia/ que inconsciente ahogó con la metralla/la razón, el derecho y la justicia /del reclamo que hacía 'la canalla..."'18. Se continúa en el plano de la metáfora fáunica para destacar el grupo de patrones del salitre, la canalla: una jauría de perros que destrozan los cuerpos de los obreros liderados por el Gran Capitán, representante del Estado. Ante la violencia estatal, que no acepta ningún parlamento, aparecen grupos que siguen la misma lógica: por la razón o la fuerza. Por eso, el poema "Sin patria y sin bandera" expresa: “... Clamando contra el infierno/ de la explotación mezquina/ más salvaje y asesino/el obrero ante el gobierno/reclamó contra su ruina,/ y éste los mató en montón/ con más saña que una fiera,/ probándoles que es tontera/ampararse en la razón"19. La explotación es simbolizada con el infierno. Esto porque el Estado hizo que la muerte sea más injusta. A pesar "que lo propio de la muerte es su injusticia, su falta de precisión, su llegar demasiado temprano o demasiado tarde. Es el abismo del tiempo presente, el reino de un tiempo sin presente" (Blanchot, 2002: 103). Pero la injusticia precoz de la muerte es sólo para los obreros. El Estado también hizo de la vida una existencia injusta. La vida de los obreros era el trabajo, transformado en un infierno: un lugar subterráneo, oscuro, fétido y atormentado por el fuego. Es imagen de la ontología del mal, la forma mítica de concebir el castigo: el infierno.

Una vez más el poeta resalta la metáfora fáunica, pero ahora en la expresión fiera. La enfatiza diciendo "más saña que una fiera". Por lo tanto

\footnotetext{
${ }^{17}$ Este texto está referido al general Roberto Silva Renard conocido como el gran responsable de la orden de matanza en la Escuela Santa María de Iquique, el 21 de diciembre de 1907. De allí el sarcástico subtítulo de este poema: “(De La Reforma de Santiago). (Para el sin par valiente Silva Renard, defensor de la Constitución, las libertades y el orden público, en la gloriosa Epopeya del 21 de diciembre de 1907)".

${ }^{18}$ Sin firma. El Pueblo Obrero, febrero 8, 1908.

${ }^{19}$ Arturo 2 ${ }^{\circ}$. Encalada. Lima. El Pueblo Obrero, abril 16, 1908.
} 
el Estado se ampara en la razón para matar irracional y salvajemente. El poeta llama la atención del obrero acerca de que, frente a la fiera estatal, no se puede tener la ingenuidad de oponer la razón humana, pues el Estado siempre transformará la razón en capital o metralla. Continua diciendo: "El general sanguinario/con saña y alevosía,/ hizo la carnicería/ entre el pueblo proletario,/ probándole no existía/ constitución ni derecho,/ ante la razón de Estado/ de proteger al malvado" ${ }^{20}$. El general sanguinario es presentado como un carnicero que transformó a los trabajadores en víctimas sacrificadas. Para los obreros "morir bien significa morir con decoro, conforme a sí mismo, y respetado los vivos. Morir bien es morir en su propia vida. Esto es una buena muerte" (Blanchot, 2002: 88). Sin embargo, los obreros no sólo mueren indignamente sino que son asesinados indecorosamente, ya sea por las masacres y el palomeo, sino también del quinteo ${ }^{21}$.

En el poema “ ¡Adelante!” de Ortúzar, aparece una pregunta existencial: “¿Qué es la vida? Solo un sueño/ ¿Qué es el hombre? Sólo un átomo/ ¿Qué es la inmensa creación?/Es miseria, nada más/ ¿Y la gloria? Fuego fatuo,/ Engañosa luz que brilla.../ La terrible realidad"22. La vida es asimilada a la metáfora onírica al estilo de Calderón de la Barca, en la que se la vincula a la necesidad de dormir y la libertad de elegir. Es la lucha entre el destino y la libertad. Pero la vida es también miseria, y este sentimiento trágico frente a la vida que tiene el obrero es como el de Segismundo: "el mayor delito del hombre es haber nacido" (Calderón de la Barca, 1984). En este caso el delito es haber nacido obrero. La única verosimilitud para darle dignidad a esta vida es "la posibilidad de morir auténticamente" (Blanchot, 2002: 107). El obrero, al igual que Segismundo, ha nacido libre, pero está condenado al encierro. Aunque es heredero legítimo de la tierra ha sido privado de todo bienestar. Continúa diciendo el mismo poema “iAdelante!”: “... Reyes, papas, generales./Señores de horca y cuchilla/ Fueron azotes del pueblo/ Engendros de la crueldad; /... / Ayer tuvieron la hoguera,/ Hoy la metralla infernal!..."23. Los obreros se unen a la gran historia herética con "los grandes personajes históricos, los héroes, que se ponen al abrigo de la muerte; y que entran en la memoria de los pueblos" (Blanchot, 2002: 82). En el pasado, a los herejes se les torturaba con distintos instrumentos. $\mathrm{Al}$ obrero

${ }^{20}$ Arturo $2^{\circ}$. Encalada. Lima. El Pueblo Obrero, abril 16, 1908.

${ }^{21}$ El quinteo "es decir elegidos al azar cada cierto número para ser eliminado" (González, 2007:133).

${ }^{22}$ Agustín Ortúzar González, El Pueblo Obrero, octubre 22, 1910.

${ }^{23}$ Ídem. 
se le tortura con el trabajo. Al hereje se le atormenta el cuerpo para salvar su alma. A los obreros se les tortura su cuerpo para salvarse el patrón. Al hereje lo tortura el sacerdote y al obrero el patrón. Al hereje se le asesinaba en la hoguera. Para los obreros el fuego de las piras fue reemplazado por el fuego de las armas; la Iglesia fue desplazada por el ejército como la nueva institución mortuoria. Por ello "al morir, creen embarcarse en un noble combate con dios" (Blanchot, 2002: 89), el dios estatal, pero en ausencia del Dios Absoluto.

\section{EL OBRERO COMO VÍCTIMA SACRIFICIAL}

Para los obreros "poder morir no es ya una cuestión desprovista de sentido. Comprenden que el objetivo es la búsqueda de la posibilidad de la muerte" (Blanchot, 2002: 82), no de cualquier muerte, sino de la muerte digna. Porque vivían cada día en la indignidad: muertos de hambre, muertos de frío, muertos de calor, muertos de sueño o muertos de cansancio. El poema titulado "Canción Nacional Moderna", destaca: “... Puro Chile tus campos floridos.../ Cementerios do yacen caídos,/ De la vida, en la lucha tenaz/ Hoy, los únicos hijos que te aman,/Por tu bien han jurado morir, / Cimentados en tu suelo el Derecho/ Hasta hacer la justicia surgir"24. Este poema es un parafraseo de la Primera Canción Nacional de Chile ${ }^{25}$. En él, "el escritor es el que escribe para poder morir y que obtiene su poder de escribir de una relación anticipada con la muerte" (Blanchot, 2002: 81). Morir luchando por un Chile libre de explotación, por un Chile igualitario. Mientras tanto, el trabajo se constituye en un campo de batalla y el desierto en cementerio donde yacen los cadáveres de los caídos en la acción laboral. Por ello se resalta que ya no se morirá por el trabajo, sino por la búsqueda de la justicia laboral. Ya no más trabajar o morir o morir trabajando, sino morir por la consecución de los derechos laborales, para que nunca más el trabajo sea sinónimo de muerte. El poema continúa diciendo: "Y si pretende el tirano altanero,/Impedir nuestra marcha triunfal,/ Defendamos la causa, cual

\footnotetext{
${ }^{24}$ Hipólito Zuleta. Taltal, septiembre 17, 1904. El Pueblo, octubre de 1904.

${ }^{25}$ Podemos encontrar en este himno reminiscencias del primer himno patrio de Chile: "El cadalso o la antigua cadena/ os presenta el soberbio español/arrancad el puñal al tirano/ quebrantad ese cuello feroz/... /Los tiranos en rabia encendidos/y tocando de cerca su fin/desplegaron la furia impotente,/que aunque en vano se halaga en destruir”. Este himno fue dejado de lado por su fuerte antiespañol algo propio de una reciente liberación. Sin embargo podemos apreciar que el poema obrero recurre a este himno porque representa su rechazo al invasor fabril.
} 
fieros/ Espartanos de fama inmortal..." ${ }^{26}$. El enemigo ya no es el imperio extranjero, sino la burguesía nacional. En conjunto con el Estado, impiden la marcha de los trabajadores para luchar por sus derechos. Así se apela a la metáfora bélica, para animar a los trabajadores a constituirse en un ejército para vencer o morir, al igual que los espartanos lo hicieron en el pasado en la Batalla de las Termópilas. "La amenaza de morir mal, como por descuido, de una muerte esencial y falsa, a tal punto que toda la vida podría depender de esa relación justa" (Blanchot, 2002: 107), es un desafío entre el mal morir (morir trabajando) y el bien morir (morir luchando).

En el poema "Al trabajador pampino" se lee: “... para sufrir/ No hay como las oficinas/Con sus faenas mezquinas /.../ No son de poder vivir/ Sino en eterno martirio;/ Sin embargo, hay un delirio/ Por acudir a la pampa / Y a velarse con un cirio..." ${ }^{27}$. Aquí se trata de la muerte de un trabajador pampino. Por ello los obreros se resisten "a la muerte anónima, es la angustia disfrazada que hace nacer el carácter anónimo de la muerte. O aún, se quiere morir, esto es noble, pero no fallecer" (Blanchot, 2002: 108). Las faenas salitreras son concebidas como espacios de sufrimiento y muerte. Pero lo peor de todo no es morir, sino morir por nada. La vida de un obrero es sufrir y por lo tanto la muerte es descanso. El trabajo es un martirio, un sacrificio en bien de los burgueses, en donde "la muerte es trivialidad, donde la misma muerte se degrada" (Blanchot, 2002: 109). A pesar del eterno martirio que es la pampa, está el delirio de la gente de todas partes por ir a trabajar a la pampa, cuando en realidad va a morir y ser velado con cirio, al igual que el cirio pascual que representa a Cristo martirizado en la cruz. Como dice Oscar Hahn: "Jesús simboliza la fuerza de trabajo esclavizada" (Campos 1987: 124).

En "Musa Pampina” se dice: “...el pobre en el mundo,.../ Está expuesto a las dolencias/Y al gran martirio profundo.../ Por un convoy desrielado,/ Un niño fue destrozado/ Daba pena y compasión.../ El cuerpo quedó en fragmentos /En ese instante fatal..."28. El pobre está condenado a sufrir, a ser víctima del patrón o de las circunstancias. El pobre es un maldito social. Lo peor de esta maldición es que mueren los niños. Los niños son también parte de la masa agonizante. "La muerte en masa, muerte en serie y de confección, hecha al por mayor para todos y donde cada uno desaparece apresuradamente, producto anónimo, objeto sin valor" (Blanchot, 2002:109).

\footnotetext{
${ }^{26}$ Hipólito Zuleta. Taltal, septiembre 17, 1904. El Pueblo, octubre de 1904.

${ }^{27}$ T.D. El Pueblo, octubre 19, 1905.

${ }^{28}$ C.A.E. Of. Alemania (Taltal). El Pueblo, octubre 24, 1905.
} 
Los obreros están en desventaja absoluta, frente a las fuerzas telúricas, una sociedad jerárquica o elite dominante, y terminan generalmente en la derrota (Latchman et al., 1956). Aquí los obreros, aunque no quieran, "todos mueren como moscas que el otoño arroja en las habitaciones, donde giran ciegamente en un vértigo inmóvil, tapizando de golpe las paredes con sus muertes estúpidas" (Blanchot, 2002: 109).

En "Canto a los Trabajadores", de Turati, se dice: “... Suprimamos la frontera/ Que a los pueblos hace arteros/ Enemigos y extranjeros/ No están fuera; están aquí/ ¡ Guerra al reino de la muerte!/ El derecho del más fuerte/ Necesario abolir" ${ }^{\prime 2}$. Hay una visión anarquista en el imaginario enemigoamigo y extranjero-nacional. El enemigo está al interior. Estos son la burguesía, la iglesia, las fuerzas armadas y el Estado: todos ellos contra el obrero. Sin embargo "la soberanía de la muerte, pese a que su omnipotencia monumental supera sus perspectivas humanas habituales, guarda al menos los rasgos de una superioridad aristocrática, temible, pero admirable" (Blanchot, 2002: 110). Pero hay que hacer una diferencia entre la muerte estéril y la muerte fértil. Aunque al Estado se le conciba como "un reino de muerte" en el que mueren los débiles, la fertilidad de la muerte es morir con propósito. El poema continúa diciendo: “... Hacer pactos es ruindad/ El rescate del trabajo/ De sus hijos provendrá/ O al trabajo darán honra/ O en la lucha morirá" ${ }^{30}$. Se hace imperioso redimir el trabajo del reinado de la muerte y transformarlo en un espacio de vida: una vez más vencer o morir para rescatar el derecho del trabajo digno. Sólo a través de la muerte fértil se puede "ser diseñadores y poetas de la propia muerte" (Blanchot, 2002: 112).

En el poema "Alzad la frente", dice: "Mártires del trabajo alzad la frente/ con actitud magnánima y sublime,/ que todo el que es esclavo y lo consciente/ del déspota burgués no se redime" ${ }^{31}$. Frente a las condiciones de trabajo como martirio, hay un llamado a la conciencia, al despertar de la condición de cautivo para autorredimirse de tal destino. Se resalta una vez más la oposición amo-esclavo. La idea es "dirigirse hacia el poder de morir por medio de la obra que escribe. Significa que la obra misma es una experiencia de la muerte, y que hay que disponer previamente de esa experiencia para llegar a la obra, y por la obra, a la muerte" (Blanchot, 2002: 81).

${ }^{29}$ Felipe Turati. El Pueblo Obrero, mayo 26, 1908.

${ }^{30}$ Ídem.

${ }^{31}$ A. Gil Veroj. El Pueblo Obrero, agosto 19, 1909. 


\section{MORIR POBRE}

En "Los dos muertos", Rafael Allende dice: "Muere un rico en su palacio/ Y la prensa, en general/ Dice... /... duelo nacional/ Muere una madre en su choza / Y su prole que solloza/ Y a un tigre el alma destroza/ Queda huérfana en el mundo..."32. Aquí hay una crítica contra las desigualdades sociales al comparar la muerte del rico y la muerte del pobre. Es el espanto de la desigualdad frente a la vida y frente a la muerte, es el horror de la pobreza: muere un rico y hay duelo; pero ante la muerte de los pobres hay indiferencia: ellos ya están muertos en vida. Es "el horror por la muerte en serie" (Blanchot, 2002: 110). El pobre muere en la invisibilidad. Su muerte es nada, porque en vida fue nadie. La muerte de una madre es execrable, que conmovería incluso a un tigre, pero nadie se inmuta, es la indiferencia absoluta. Esto genera en el poeta una profunda "angustia de la muerte anónima” (Blanchot, 2002: 114). Luego continúa diciendo: /Calláis ¿ No veis, mercenarios/ Que en esos dolores diarios/ Sí que hay duelo nacional?" ${ }^{33}$. La miseria no logra sensibilizar a los medios de comunicación porque son cómplices del capital. La muerte del pobre-obrero es una "muerte extranjera que los hace morir en el desamparo de la extrañeza" (Blanchot, 2002: 112). Y aún más, la muerte de una madre o de un padre sucede frecuente y cotidianamente en el mundo obrero, pero carecen de toda trascendencia social y metafísica. Esto nos recuerda a Armando Uribe, cuando dice que "hay un vacio total de la muerte después de la muerte" (Triviños y Aldunate, 2006: 81).

En "Carta abierta Al Señor Gerente del FFCC del Salitre", un poeta obrero dice "... Oír un jefe el clamor/ De tantos pobres obreros/ Porque ellos son los primeros/ Que siempre a la muerte van..." ${ }^{34}$. La pobreza está relacionada simbólicamente con lo de abajo, lo infernal y la tierra. Los obreros mueren, pero los patrones lo niegan: "Si negáramos la muerte, es como si negáramos los aspectos graves y difíciles de la vida, como si sólo tratásemos de acoger las partes mínimas de la vida" (Blanchot, 2002: 114). La negación de los patrones no implica incredulidad, sino indiferencia. Niegan la muerte del obrero: antes le han negado su humanidad. El pobre deviene en víctima; de allí, las frecuentes expresiones de: "pobre hombre", "pobre obrero"; "pobre mujer". Son víctimas de condiciones laborales, viviendas y alimenticias,

\footnotetext{
${ }^{32}$ Juan Rafael Allende. El Pueblo, julio 25, 1901.

${ }^{33}$ Ídem.

${ }^{34}$ No Caroca. Estación Carpas. El Pueblo, diciembre 20, 1901.
} 
a causa de las cuales los pobres mueren precozmente. Los obreros ven en "la muerte la sabia compañera de la vida, donde el espanto es éxtasis, donde la celebración se lamenta y la lamentación glorifica, el espacio mismo hacia el cual se precipitan todos los mundos como hacia su realidad más próxima y más verdadera" (Blanchot, 2002: 114).

En "Sensible desgracia en North Lagunas o Percances de Roto chileno", el poeta destaca “... Se fue a su trabajo Pío/ Con gusto y muy complacido/Y su salud buena y sana/ La muerte estaba cercana/ Pero él se fue muy ufano/ Como es lícito y llano/ Con la mayor alegría/pero pasó la Parca impía" ${ }^{35}$. Aquí el poeta nos muestra, con cierto eufemismo, a un trabajador de nombre Pío, que significa alguien piadoso, benigno, misericordioso, compasivo, justo y honrado. Un obrero al que le gusta ir a su trabajo con alegría y gallardía, a pesar de las condiciones mortales. Sin embargo la muerte ronda a este santo trabajador, "porque la muerte, está más pronta, porque es nuestro destino" (Blanchot, 2002: 131). La muerte es imaginada como la Parca impía, vinculada a la mitología romana, representada como tres hermanas: Cloto, Láquesis y Átropos. Figuras de ancianas, de las cuales la primera hilaba, la segunda devanaba y la tercera cortaba el hilo de la vida del hombre. Esto nos lleva a pensar que el hilo de la vida del obrero es más fino y fácil de cortar; por ello los obreros demuestran "ser capaces de aceptar tranquilamente la muerte" (Blanchot, 2002: 78). Estas tres imágenes de la muerte también las podemos asimilar a las instituciones mortuorias que sacrifican al obrero: la economía, la política y la religión.

El poeta continúa diciendo: "Envío la condolencia/ Por mi amado compañero/ De trabajo.../ Porque perdió la existencia/ Resignación y paciencia /.../ De aquella trágica muerte ${ }^{36}$. Se dejan ver huellas del criollismo en donde aparece la idea fatalista de que el obrero debe luchar contra la naturaleza indómita; el obrero, víctima del destino, siempre pierde. Los únicos sentimientos que caben al respecto son resignación y paciencia frente al hado ineluctable de la muerte. ¿Qué les queda a los vivos? Transformar la muerte en algo fértil. Continúa diciendo el poeta: "Lloró Antonino el menor/ Domingo también lloraba /.../ Su hermano con gran dolor/Al dar su último fulgor/ Pegó el vuelo a la otra vida/ Marchitando la tumba fría/ Cruzo escabroso el camino ${ }^{37}$. Así describe los últimos momentos de vida del obrero y el dolor que causa la pérdida entre sus hijos y hermanos, porque se trata

\footnotetext{
${ }^{35}$ Casiano Aguirre E. Of. Buenaventura. El Pueblo, marzo 26, 1903.

${ }^{36}$ Ídem.

${ }^{37}$ Idem.
} 
de muertes infaustas, trágicas e inesperadas. Es la realidad entre el "morir de la gran muerte o de la pequeña muerte" (Blanchot, 2002: 111). Lamentablemente aquí es una muerte pequeña. Se trata de un trabajador adulto, de buena salud que muere precoz y trágicamente, en el fulgor de su vida. Es "la mala muerte, la que tiene la brutalidad de un acontecimiento y de un azar, no llevada a su esencia secreta" (Blanchot, 2002: 134). Se insiste en las representaciones grecorromanas del morir: la vida y la muerte como un delgado hilo entre el calor de la vida y el frío de la muerte; el camino llano de la vida y el escabroso recorrer de la muerte. Pero también la muerte es representada como la otra vida, no es el fin de la vida, sino otra vida sin pena ni glorias: sólo es otra vida. También encontramos la muerte representada en la metáfora del vuelo, ya que hay una frontera liminal entre la vida y la muerte que no se puede pasar con un salto, sólo volando. Es el poder del muerto, pero que no tiene poder sobre los vivos: sólo se va.

El poeta termina diciendo: "Al fin su empresa cumplió/ El amigo más querido/ Con el corazón herido/ En el mundo nos dejó/ El pésame les doy yo/ De este lejano lugar/ Niños no debéis llorar/ Que a la celestial mansión,/ El que perdió razón/ Se fue para eternizar" ${ }^{\prime 3}$. Es el dolor de la pérdida ante el eterno vuelo del amigo. Hay un abismo lejano entre este mundo y el otro mundo, entre la vida y la morada de los muertos. Pero se llama a no llorar, porque el muerto fue a un lugar mejor: a su celestial mansión. Así el poema se presenta como un poema mortuorio, en donde se "escribe para morir, para dar a la muerte su posibilidad esencial, por lo que es esencialmente muerte, fuente de invisibilidad" (Blanchot, 2002: 134). Es muy significativa esta creencia en que el muerto pudiera tener lo que nunca logró en esta tierra: tener una casa. En la muerte no sólo tendrá una casa, sino que tiene como herencia una mansión, como los palacios de los dueños del salitre. Esto tiene relación con las satisfacciones diferidas de los cristianos. Por lo tanto, terminamos preguntando, con la expresión bíblica que Maurice Blanchot hace suya: "Oh muerte ¿̇ónde está tu victoria? Pueden decirlo, pero a condición de agregar: ¿Dónde está tu aguijón?” (Blanchot, 2002: 88).

\section{REFERENCIAS}

Aguilera, M. y Zúñiga, C. (2006). Políticas estatales de asistencia social en Chile: El problema de la leche (1930-1970). Seminario de grado para optar al Grado

${ }^{38}$ Ídem. 
de Licenciada en Historia. Facultad de Filosofía y Humanidades, Programa de Pregrado, Departamento de Ciencias Históricas, Universidad de Chile.

Baudrillard, J. (1993). El intercambio simbólico y la muerte. Caracas: Monteávila. Belli, Carlos (1989). “Oscar Hahn, Arte de morir”. En: Lihn, E. y Lastra, P. (Eds.), Asedios a Oscar Hahn (pp. 111-112). Santiago de Chile: Edit. Universitaria.

Berger, P. L. y Luckmann, T. (2003). La construcción social de la realidad. Buenos Aires: Amorrortu.

Blanchot, M. (2002). El espacio literario. Madrid: Editora Nacional.

Calderón de la Barca, P. (1984). La vida es sueño. Santiago: Ercilla.

Campos, J. (1987). "La transformación de la visión de la muerte en la poesía de Oscar Hahn”. En La joven poesía chilena en el período 1961-1973 (Gonzalo Millán, Waldo Rojas, Oscar Hahn) (pp. 99-138). Concepción-Minneapolis: Lar - Institute for the Study of Ideologies and Literature.

Espinoza, C. (2000). "Diario de muerte de Enrique Lihn: la escritura sobre la línea de la muerte”. Estudios Filológicos 35, 151-166.

Fromm, E. (1992). El corazón del hombre. su potencia para el bien y el mal. Buenos Aires: FCE.

Galindo, O. (2000). "La poesía de Oscar Hahn: los símbolos despavoridos”. Estudios Filológicos 35, 167-181.

González, S. (2007). Ofrenda de una masacre, claves e indicios históricos de la emancipación pampina de 1907. Santiago: Lom.

Hegel, G.W.F. (1997). Lecciones sobre la filosofía de la historia universal I. Barcelona: Ataya.

Hobbes, T. (1998). Leviatán. O la materia, forma y poder de una república eclesiástica y civil. México: FCE.

Latchman, R.; Montenegro E. y Vega, M. (1956). El criollismo. Santiago: Universitaria. Versión on line. http://www.memoriachilena.cl/temas/index. asp?id_ut=elcriollismo

Lihn, E. (1989). “Arte del Arte de morir: primera lectura de un libro de Oscar Hahn”. En: Lihn, E. y Lastra, P. (Eds.), Asedios a Oscar Hahn (pp. 99-104). Santiago de Chile: Edit. Universitaria.

Lillo, B. (2008). Obras completas. Álvarez I. y Bello, H. (Eds.). Santiago: Universidad Alberto Hurtado.

Marx, C. (1987). El capital. Crítica de la economía política. México: FCE.

Triviños, G. (1993). La metamorfosis de la muerte en la poesía de Darío, Huidobro y Parra". Recuperado de http://www.nicanorparra.uchile.cl/estudios/ metamorfosis.html

(2007). "Parra, pero también Quino: Reescritura de una obsesión”. Atenea $495,35-52$.

Triviños, G. y Aldunate, P. (2006). "El poeta y la muerte en la poesía de Armando Uribe Arce. Hacia una física-poética de la muerte”. Atenea 493, 63-86.

Yáñez, J. (2008). "Por una legislación social en Chile. El movimiento de los panaderos (1888-1930)". Historia 41(2), 495-532. Recuperado de http://www. scielo.cl/scielo.php?pid=S0717-71942008000200006\&script=sci_arttext 